\title{
Evolution of the $\mathbf{C}_{4}$ phosphoenolpyruvate carboxylase promoter of the $\mathrm{C}_{4}$ species Flaveria trinervia: the role of the proximal promoter region
}

\author{
Sascha Engelmann ${ }^{1}$, Corinna Zogel ${ }^{1,2}$, Maria Koczor ${ }^{1}$, Ute Schlue ${ }^{1}$, \\ Monika Streubel ${ }^{1}$ and Peter Westhoff*1
}

\begin{abstract}
Address: ${ }^{1}$ Institut für Entwicklungs- und Molekularbiologie der Pflanzen, Heinrich-Heine-Universität, Universitätsstr. 1, 40225 Düsseldorf, Germany and 2Institut für Humangenetik der Universität Duisburg-Essen, Hufelandstr. 55, 45122 Essen, Germany

Email: Sascha Engelmann - engelmas@uni-duesseldorf.de; Corinna Zogel - corinna.zogel@uni-due.de; Maria Koczor - Maria.Koczor@uniduesseldorf.de; Ute Schlue - Ute.Schlue@uni-duesseldorf.de; Monika Streubel - streubel@uni-duesseldorf.de; Peter Westhoff* - west@uniduesseldorf.de

* Corresponding author
\end{abstract}

Published: 21 January 2008

BMC Plant Biology 2008, 8:4 doi:10.1 186/I47I-2229-8-4

This article is available from: http://www.biomedcentral.com/I47I-2229/8/4

(c) 2008 Engelmann et al; licensee BioMed Central Ltd.

This is an Open Access article distributed under the terms of the Creative Commons Attribution License (http://creativecommons.org/licenses/by/2.0), which permits unrestricted use, distribution, and reproduction in any medium, provided the original work is properly cited.
Received: 8 November 2007

Accepted: 21 January 2008

\begin{abstract}
Background: The key enzymes of photosynthetic carbon assimilation in $\mathrm{C}_{4}$ plants have evolved independently several times from $C_{3}$ isoforms that were present in the $C_{3}$ ancestral species. The $\mathrm{C}_{4}$ isoform of phosphoenolpyruvate carboxylase (PEPC), the primary $\mathrm{CO}_{2}$-fixing enzyme of the $\mathrm{C}_{4}$ cycle, is specifically expressed at high levels in mesophyll cells of the leaves of $\mathrm{C}_{4}$ species. We are interested in understanding the molecular changes that are responsible for the evolution of this $\mathrm{C}_{4}{ }^{-}$ characteristic PEPC expression pattern, and we are using the genus Flaveria (Asteraceae) as a model system. It is known that cis-regulatory sequences for mesophyll-specific expression of the PpcAI gene of $F$. trinervia $\left(C_{4}\right)$ are located within a distal promoter region (DR).

Results: In this study we focus on the proximal region (PR) of the $P p c A l$ promoter of $F$. trinervia and present an analysis of its function in establishing a $\mathrm{C}_{4}$-specific expression pattern. We demonstrate that the PR harbours cis-regulatory determinants which account for high levels of PEPC expression in the leaf. Our results further suggest that an intron in the $5^{\prime}$ untranslated leader region of the $P R$ is not essential for the control of $P p c A /$ gene expression.

Conclusion: The allocation of cis-regulatory elements for enhanced expression levels to the proximal region of the PPCAl promoter provides further insight into the regulation of PEPC expression in $\mathrm{C}_{4}$ leaves.
\end{abstract}

\section{Background}

About $90 \%$ of terrestrial plant species, including major crops such as rice, soybean, barley and wheat, assimilate $\mathrm{CO}_{2}$ via the $\mathrm{C}_{3}$ pathway of photosynthesis. Ribulose-1,5bisphosphate carboxylase/oxygenase (Rubisco) acts as the primary $\mathrm{CO}_{2}$-fixing enzyme of $\mathrm{C}_{3}$ photosynthesis, but its ability to use $\mathrm{O}_{2}$ as a substrate instead of $\mathrm{CO}_{2}$ results in the energy-wasting process of photorespiration. The photosynthetic $\mathrm{C}_{4}$ cycle represents an addition to the $\mathrm{C}_{3}$ pathway which acts as a pump that accumulates $\mathrm{CO}_{2}$ at the site of Rubisco so that the oxygenase activity of the enzyme is inhibited and photorespiration is largely suppressed. $\mathrm{C}_{4}$ 
plants therefore achieve higher photosynthetic capacities and better water- and nitrogen-use efficiencies when compared with $\mathrm{C}_{3}$ species [1].

$\mathrm{C}_{4}$ photosynthesis is characterized by the coordinated division of labour between two morphologically distinct cell types, the mesophyll and the bundle-sheath cells. The correct functioning of the $\mathrm{C}_{4}$ cycle depends upon the strict compartmentalization of the $\mathrm{CO}_{2}$ assimilatory enzymes into either mesophyll or bundle-sheath cells [2]. Phosphoenolpyruvate carboxylase (PEPC), which serves as the actual $\mathrm{CO}_{2}$ pump of the $\mathrm{C}_{4}$ pathway, is specifically expressed in the mesophyll cells of $\mathrm{C}_{4}$ leaves. This enzyme is not an unique feature of $\mathrm{C}_{4}$ species; other PEPC isoforms with different catalytic and regulatory properties are found in both photosynthetic and non-photosynthetic tissues of all plants where they participate in a variety of metabolic processes, e.g. replenishment of citric acid cycle intermediates and regulation of guard cell movement [3].

The polyphyletic origin of $\mathrm{C}_{4}$ photosynthesis suggests that the photosynthetic $\mathrm{C}_{4}$ isoforms of PEPC have evolved independently several times from non-photosynthetic $\mathrm{C}_{3}$ isozymes [4]. During the evolution of $\mathrm{C}_{4}$ PEPC genes from ancestral $\mathrm{C}_{3}$ genes, changes in expression strength and organ- and cell-specific expression patterns must have occurred. While $\mathrm{C}_{4}$ PEPC genes are highly expressed in the mesophyll cells of the leaf, the $\mathrm{C}_{3}$ isoform genes are only moderately transcribed in all plant organs [5-8].

To investigate the molecular evolution of a $\mathrm{C}_{4}$ PEPC gene we are using the genus Flaveria (Asteraceae) as a model system. This genus includes $\mathrm{C}_{4}$ and $\mathrm{C}_{3}$ as well as $\mathrm{C}_{3}-\mathrm{C}_{4}$ intermediate species $[9,10]$ and thus provides an excellent system for studying the evolution of the $\mathrm{C}_{4}$ photosynthetic pathway [11]. Previous studies on the ppcA1 gene of $F$. trinervia, encoding the $\mathrm{C}_{4}$ isoform of PEPC, revealed that the strong mesophyll-specific expression is largely regulated at the transcriptional level and that the available 2188 bp (with reference to the AUG start codon of the $p p c A 1$ reading frame) of the 5 ' flanking sequences contain all the essential cis-regulatory elements for high and mesophyll-specific expression [12]. Two parts of the ppcA1 promoter of $F$. trinervia, a proximal region (PR) up to -570 in combination with a distal region (DR) from -1566 to 2141, are sufficient to direct a high mesophyll-specific expression of a $\beta$-glucuronidase (GUS) reporter gene in transgenic $F$. bidentis $\left(\mathrm{C}_{4}\right)$ plants [13]. The orthologous, 2538 bp comprising ppcA1 promoter of the $\mathrm{C}_{3}$ species $F$. pringlei displays only weak activity in all interior leaf tissues in transgenic $F$. bidentis, but fusion of the $\mathrm{C}_{4}$-DR to this $\mathrm{C}_{3}$ PEPC promoter leads to a confinement of GUS expression to the mesophyll [13]. Analysis of the $\mathrm{C}_{4}$-DR revealed that the 41-bp module MEM1 (mesophyll expression module 1 ) is responsible for the $\mathrm{C}_{4}$-character- istic spatial expression pattern of the $p p c A 1$ gene of $F$. trinervia. Furthermore, it was shown that a high level of expression in the mesophyll requires an interaction of the $\mathrm{C}_{4}$-DR with the $\mathrm{C}_{4}$-PR. This suggests that quantity elements for an elevated expression of the $\mathrm{C}_{4}$ PEPC gene are located within the PR of the 5' flanking sequences [13].

Using the yeast one-hybrid system, Windhövel and colleagues $[14,15]$ identified four different proteins which bind to the PR of the $p p c A 1$ promoter of $F$. trinervia, but not to the corresponding part of the ppcA1 promoter of $F$. pringlei. These proteins (named FtHB1 to FtHB4) belong to the class of zinc finger homeodomain proteins (ZFHD). Two regions of the $\mathrm{C}_{4}$-PR specifically interact with the FtHB proteins in vitro: an intron sequence within the 5 ' untranslated leader region and a DNA fragment that is located upstream of the putative TATA-box. To the latter one, the FtHB proteins showed a much lower binding affinity [14]. Homeobox proteins are known to act as transcriptional regulators of eukaryotic gene expression [16$18]$, and the fact that the FtHB homeobox proteins interact specifically with the PR of the $p p c A 1$ promoter of $F$. trinervia makes them prime candidates for transcription factors that are involved in the establishment of the $\mathrm{C}_{4}{ }^{-}$ characteristic expression pattern of the $\mathrm{C}_{4} p p c A 1$ gene.

In this study we have investigated the role of the proximal promoter region of the $p p c A 1$ gene of $F$. trinvervia with regard to its high and mesophyll-specific expression by transgenic analyses in the closely related $\mathrm{C}_{4}$ species $F$. bidentis. We demonstrate that the proximal promoter region of the $p p c A 1$ gene contains cis-regulatory elements that determine promoter strength. Furthermore, we show that the deletion of an intron located in the 5' untranslated segment of $p p c A 1$ does not alter promoter activity in transgenic F. bidentis.

\section{Results and discussion Experimental strategy}

We are interested in elucidating the molecular events that are crucial for the evolution of the high and mesophyllspecific expression of the $\mathrm{C}_{4}$ phosphoenolpyruvate carboxylase gene ( $p p c A 1)$ of the $\mathrm{C}_{4}$ plant $F$. trinervia. In this study we focus on the proximal promoter region (PR) of the $p p c A 1$ gene with respect to its function in establishing the $\mathrm{C}_{4}$-characteristic expression pattern. We performed a comparative analysis of three different promoter-GUS fusion constructs (Fig. 1) in transgenic F. bidentis plants. F. bidentis is a close relative to $F$. trinervia, but in contrast to F. trinervia this $\mathrm{C}_{4}$ species is transformable by Agrobacterium tumefaciens mediated gene transfer [19] and was therefore chosen for these experiments.

Construct $p p c A-\mathrm{PR}_{\mathrm{Ft}}-\mathrm{DR}(+)_{\mathrm{Ft}}$ served as a reference because it was already known from previous experiments that a 


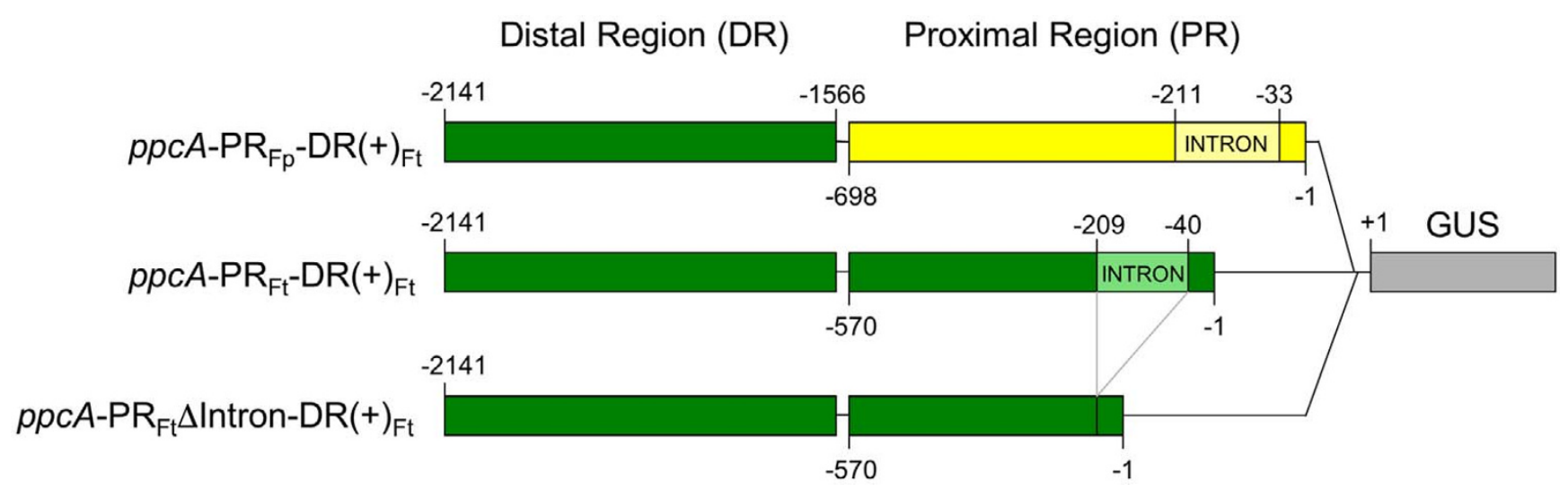

Figure I

Schematic presentation of the promoter-GUS fusion constructs used for the transformation of Flaveria bidentis $\left(\mathrm{C}_{4}\right)$.

combination of the distal (DR) and the proximal (PR) promoter regions was sufficient to direct a high and mesophyll specific expression of a GUS reporter gene in $F$. bidentis [13]. To find out if the PR of the $\mathrm{C}_{4}$ ppcA1 promoter contains quantity elements conferring high expression in the mesophyll cells we designed construct $p p c A$ $\mathrm{PR}_{\mathrm{Fp}}-\mathrm{DR}(+)_{\mathrm{Ft}}$. Here, the $\mathrm{C}_{4}$-PR was exchanged for its counterpart from the orthologous $p p c A 1$ gene of the $\mathrm{C}_{3}$ species $F$. pringlei. Deletion of the intron sequences in the $5^{\prime}$ untranslated segment of promoter construct $p p c A-\mathrm{PR}_{\mathrm{Ft}}{ }^{-}$ $\mathrm{DR}(+)_{\mathrm{Ft}}$ resulted in the formation of construct $p p c A-\mathrm{PR}_{\mathrm{Ft}}{ }^{-}$ $\Delta$ Intron-DR $(+)_{\mathrm{Ft}}$. Thereby a putative binding site for the ZF-HD proteins FtHB1 to FtHB4 [14] was removed from the $\mathrm{C}_{4}$-PR. Hence, this chimeric promoter-GUS fusion could answer the question whether the intron-located putative binding site of the FtHB proteins is necessary for the establishment of the $\mathrm{C}_{4}$-specific $p p c A 1$ expression pattern.

The proximal region of the ppcAl promoter of $F$. trinervia harbours cis-regulatory elements for a high level of PEPC expression in the mesophyll

Gowik et al. [13] assumed that the PR of the ppcA1 promoter of $F$. trinervia comprises cis-regulatory determinants conferring high levels of expression in mesophyll cells of $\mathrm{C}_{4}$ leaves. To examine whether the PR actually harbours such quantity elements we analyzed the GUS expression patterns of constructs $p p c A-\mathrm{PR}_{\mathrm{Ft}}-\mathrm{DR}(+)_{\mathrm{Ft}}$ and $p p c A-\mathrm{PR}_{\mathrm{Fp}}{ }^{-}$ $\mathrm{DR}(+)_{\mathrm{Ft}}$ (Fig. 1) in transgenic F. bidentis.

In F. bidentis plants that had been transformed with promoter construct $p p c A-\mathrm{PR}_{\mathrm{Ft}} \mathrm{DR}(+)_{\mathrm{Ft}^{\prime}}$ GUS expression was exclusively detected in the mesophyll cells of the leaves (Fig. 2A). This observation shows that the DR and PR of the $p p c A 1$ promoter together are sufficient for a high and mesophyll-specific expression of the linked GUS reporter gene and therefore confirms the results obtained by
Gowik et al. [13]. Replacement of the $\mathrm{C}_{4}$-PR by the corresponding region from the $p p c A 1$ promoter of $F$. pringle $i$ (construct $p p c A-\mathrm{PR}_{\mathrm{Fp}}-\mathrm{DR}(+)_{\mathrm{Ft}}$ ) did not cause any alteration in the cellular GUS expression pattern when compared to $p p c A-\mathrm{PR}_{\mathrm{Ft}}-\mathrm{DR}(+)_{\mathrm{Ft}} ;$ GUS activity was still restricted to the mesophyll compartment (Fig. 2B). However, both chimeric promoters differed greatly in transcriptional strength. Quantitative GUS assays revealed that promoter activity was decreased by a factor of 15 when the $\mathrm{C}_{4}$-PR was substituted for the $\mathrm{C}_{3}$-PR (Fig. 2D). This clearly demonstrated that the $\mathrm{C}_{4}$-characteristic transcription-enhancing cis-regulatory elements must be located within the proximal region of the $p p c A 1$ promoter of $F$. trinervia. The low expression level of construct $p p c A$ $\mathrm{PR}_{\mathrm{Fp}}-\mathrm{DR}(+)_{\mathrm{Ft}}$ could be the result of an absence of transcription-enhancing cis-regulatory elements in the $\mathrm{C}_{3}-\mathrm{PR}$, but it might also be caused by problems in the interaction of the $\mathrm{C}_{4}$-DR and the $\mathrm{C}_{3}$-PR.

\section{The intron in the $C_{4}-P R$ is not required for the establishment of a $C_{4}$-specific expression pattern of the ppcAl gene of $F$. trinervia}

The 5 ' untranslated region of the $p p c A 1$ gene of $F$. trinervia contains an intron between positions -209 and $-40(+1$ refers to the starting point of translation). Introns are of prominent importance for the molecular evolution of eukaryotic genomes by facilitating the generation of new genes via exon-shuffling and by providing the possibility to create multiple proteins from a single gene via alternative splicing [20-22]. Furthermore, it has been shown that introns can affect many different stages of gene expression, including both transcriptional and post-transcriptional mechanisms [22-24].

Here, we wanted to investigate whether the first intron of the ppcA1 gene of $F$. trinervia is essential for establishing the $\mathrm{C}_{4}$-characteristic expression pattern. We therefore 

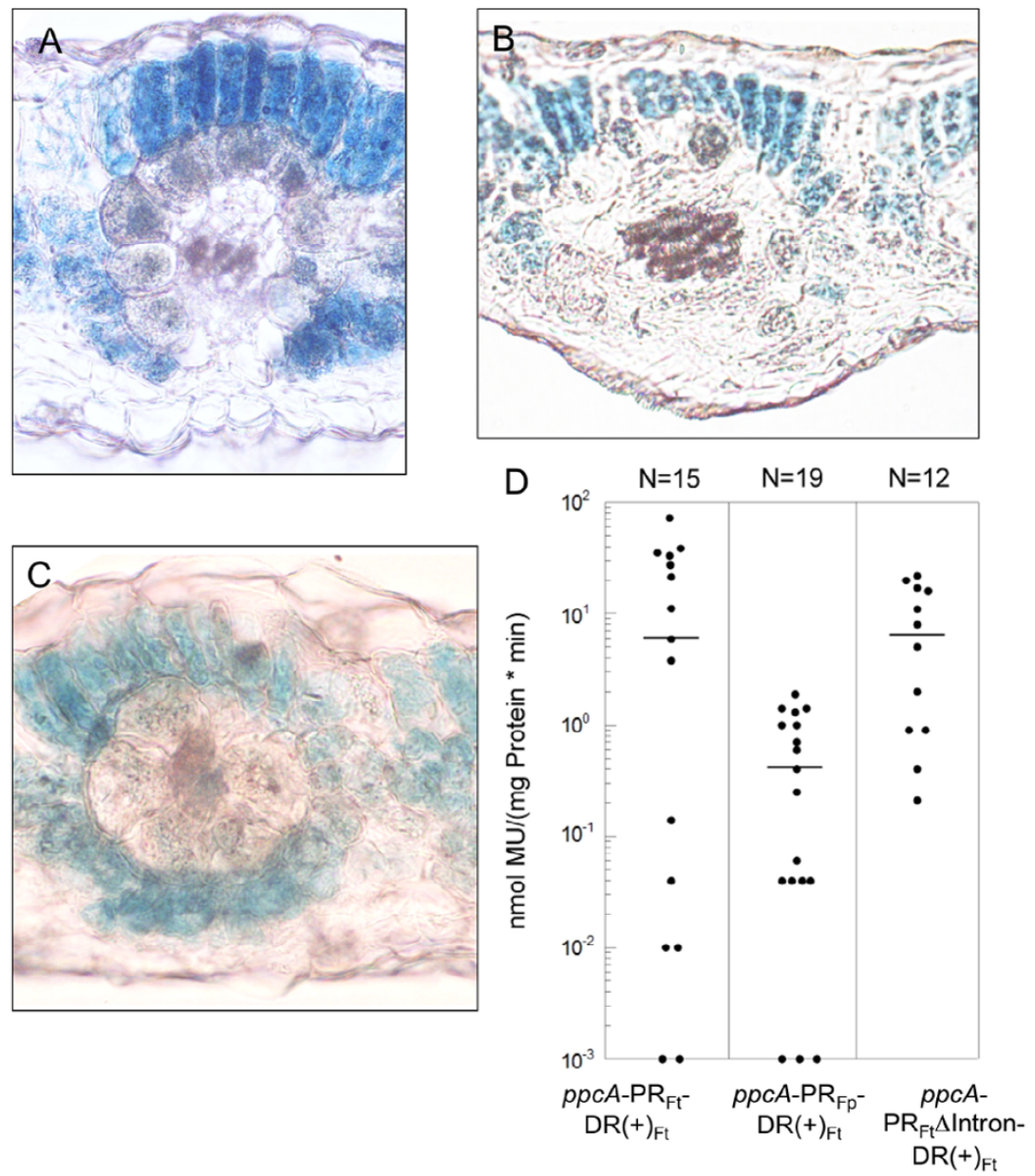

\section{Figure 2}

(A) to (C): Histochemical localization of GUS activity in leaf sections of transgenic $F$. bidentis plants transformed with constructs ppcA-PR $\mathrm{Ft}^{-D R}(+)_{\mathrm{Ft}}(\mathbf{A})$, $p p c A-\mathrm{PR}_{\mathrm{Fp}}-\mathrm{DR}(+)_{\mathrm{Ft}}(\mathbf{B})$ or $p p c A-\mathrm{PR}_{\mathrm{Ft}} \Delta$ Intron-DR(+) $)_{\mathrm{Ft}}(\mathbf{C})$. Incubation times were $6 \mathrm{~h}(\mathbf{A}, \mathbf{C})$ and $20 \mathrm{~h}$ (B). (D): GUS activities in leaves of transgenic F. bidentis plants. The numbers of independent transgenic plants tested (N) are indicated at the top of each column. Median values (black lines) of GUS activities are expressed in nanomoles of the reaction product 4-methylumbelliferone (MU) generated per milligram of protein per minute.

deleted the intron sequences from the $\mathrm{C}_{4}$-PR in construct $p p c A-\mathrm{PR}_{\mathrm{Fp}}-\mathrm{DR}(+)_{\mathrm{Ft}}$, resulting in the formation of construct $p p c A-\mathrm{PR}_{\mathrm{Ft}} \Delta$ Intron-DR(+) $\mathrm{Ft}$ (Fig. 1). The histochemical analysis of transgenic $F$. bidentis plants demonstrated that the $p p c A-\mathrm{PR}_{\mathrm{Ft}} \Delta \mathrm{Intron}-\mathrm{DR}(+)_{\mathrm{Ft}}$ promoter was exclusively active in the mesophyll cells of the leaves (Fig. 2C). The quantitative examination of GUS activity (Fig. 2D) also revealed no significant differences between $p p c A-\mathrm{PR}_{\mathrm{Ft}} \Delta \mathrm{In}$ tron-DR $(+)_{\mathrm{Ft}}\left(6,5 \mathrm{nmol} \mathrm{MU} /\left(\mathrm{mg}^{*} \min \right)\right)$ and $p p c A-\mathrm{PR}_{\mathrm{Ft}}{ }^{-}$ $\mathrm{DR}(+)_{\mathrm{Ft}}\left(5,9 \mathrm{nmol} \mathrm{MU} /\left(\mathrm{mg}^{*} \mathrm{~min}\right)\right)$. These data suggest that the $5^{\prime}$ located intron of $p p c A 1$ does not contain any cis-regulatory elements that are essential for achieving high mesophyll-specific expression of a reporter gene. Accordingly, the specific binding of the FtHB proteins to this intron that was observed in vitro and in yeast onehybrid experiments $[14,15]$ has no in planta relevance concerning the regulation of $p p c A 1$ expression in $\mathrm{C}_{4}$ leaves. However, our results do not necessarily indicate that the intron is completely dispensable for the regulation of $p p c A 1$ gene expression. It is known that $\mathrm{C}_{4}$ gene transcription is modulated by various metabolites such as sugar hexoses [25-27], and we cannot exclude that the first intron of the $p p c A 1$ gene of $F$. trinervia might be involved in the metabolic control of gene expression.

\section{Comparison of proximal ppcA promoter sequences from different Flaveria species}

As reported above, cis-regulatory elements for leaf-specific enhanced transcription of the ppcA1 gene of $F$. trinervia could be allocated to the PR of the 5 ' flanking sequences, but their exact nature and localization was still unclear. To identify potential cis-regulatory enhancing elements, a 
sequence comparison between the PR of the ppcA1 gene of F. trinervia and equivalent promoter sequences from other Flaveria species was performed (Fig. 3). This approach was chosen because it was already known from northern analyses of $p p c A$ transcript levels in different Flaveria species that $p p c A$ RNA amounts in leaves increase gradually from $\mathrm{C}_{3}$ to $\mathrm{C}_{4}$ species [28]. This is consistent with the important function of PEPC during $\mathrm{C}_{4}$ photosynthesis. The $\mathrm{C}_{4}$-like species $F$. brownii and $F$. vaginata exhibited $p p c A$ RNA levels that were comparable to those of the $\mathrm{C}_{4}$ plants F. bidentis and $F$. trinervia, and even in $F$. pubescens, a $\mathrm{C}_{3}-\mathrm{C}_{4}$ intermediate with rather poorly developed $\mathrm{C}_{4}$-characteristic traits, $p p c A$ transcript accumulation in the leaves was significantly higher than in the $\mathrm{C}_{3}$ species $F$. cronquistii and F. pringlei [28].

Searching for known plant cis-regulatory DNA elements in the PLACE database [29] resulted in the identification of two distinct sequence motifs which might be involved in the regulation of $p p c A$ expression levels (Fig. 3). Both of them, a putative MYB transcription factor binding site (GTTAGTT, [30]) and a CCAAT box [31], are present in all examined $\mathrm{C}_{3}-\mathrm{C}_{4}, \mathrm{C}_{4}$-like and $\mathrm{C}_{4}$ species, but are missing in the two $\mathrm{C}_{3}$ species (Fig. 3). Thus, these sequences are prime candidates for transcription-enhancing cis-regulatory elements. CCAAT boxes are common sequences that are found in the $5^{\prime}$ untranslated regions of many eukaryotic genes [32]. They are able to regulate the initiation of transcription by an interaction of CCAAT-binding transcription factors with the basal transcription initiation complex [33]. There is no unifying expression pattern for plant genes containing putative CCAAT promoter elements, indicating that they may play a complex role in regulating plant gene transcription [32]. MYB proteins, on the other hand, comprise one of the largest families of transcription factors in plants, with almost 200 different MYB genes present in the Arabidopsis genome [34-36]. To test the physiological importance of the putative MYB and CCAAT binding sites (that are located within the PR of the $p p c A 1$ promoter of $F$. trinervia) it will be crucial to inactivate these sequences in construct $p p c A-\mathrm{PR}_{\mathrm{Ft}} \Delta$ Intron$\mathrm{DR}(+)_{\mathrm{Ft}}$ by site-directed mutagenesis and to investigate whether this results in a decrease of reporter gene expression in the leaves of transgenic $F$. bidentis plants.

When searching for quantity elements in the PR of the $p p c A 1$ promoter of $F$. trinervia, one should always keep in mind that high levels of reporter gene expression in the leaf mesophyll require the synergistic action of the distal and proximal promoter regions. The $\mathrm{C}_{4}$-PR alone exhibits very low transcriptional activity in all interior leaf cell types of transgenic F. bidentis [37], indicating that the cisregulatory elements for enhanced expression are only functional when the $\mathrm{C}_{4}$-PR is combined with the cognate $\mathrm{C}_{4}$-DR. One may speculate that a strong expression of the
ppcA1 gene in the mesophyll cells of $F$. trinervia depends on the interaction of trans-acting factors which bind to cisregulatory elements within the PR with other transcription factors that are recruited to $\mathrm{C}_{4}$-specific cis-regulatory determinants in the DR. In the future, further dissection of the $\mathrm{C}_{4}$-PR of $F$. trinervia and expression analyses of additional DR-PR combinations from $p p c A$ promoters of different Flaveria species in transgenic $F$. bidentis will be useful for uncovering the control of $p p c A$ expression levels in $\mathrm{C}_{4}$ leaves.

\section{Conclusion}

In this study, we have demonstrated that the proximal region $(-570$ to -1$)$ of the $p p c A 1$ promoter of $F$. trinervia $\left(\mathrm{C}_{4}\right)$ harbours cis-regulatory elements conferring high expression levels in leaf mesophyll cells of transgenic $F$. bidentis $\left(\mathrm{C}_{4}\right)$. It was further demonstrated that the deletion of an intron in the 5 ' untranslated leader region does not affect the $\mathrm{C}_{4}$-specific ppcA1 expression pattern and strength, indicating that the previously isolated zinc finger-homeobox transcription factors that specifically interact with this intron in vitro are not involved in regulating ppcA1 expression levels. Sequence comparisons resulted in the identification of potential cis-regulatory elements in the proximal part of the $p p c A 1$ promoter that might play a role in controlling $p p c A 1$ expression quantity. Genetic manipulation of these sequences and subsequent analyses in transgenic $F$. bidentis will clarify whether they are able to direct high ppcA1 expression levels in $\mathrm{C}_{4}$ leaves.

\section{Methods \\ Construction of chimeric promoters}

DNA manipulations and cloning were performed according to Sambrook and Russell [38]. The construction of the promoter-GUS fusion $p p c A-\mathrm{PR}_{\mathrm{Ft}}-\mathrm{DR}(+)_{\mathrm{Ft}}$ has been described in detail [13]. Plasmids $p p c A-S-F p[39]$ and $p p c A$ $\mathrm{PR}_{\mathrm{Ft}}-\mathrm{DR}(+)_{\mathrm{Ft}}$ served as the basis for the production of $p p c A-\mathrm{PR}_{\mathrm{Fp}}-\mathrm{DR}(+)_{\mathrm{Ft}}$. The distal region (-2141 to -1566) of the $p p c A 1$ promoter of $F$. trinervia was excised from $p p c A$ $\mathrm{PR}_{\mathrm{Ft}}-\mathrm{DR}(+)_{\mathrm{Ft}}$ by digestion with $\mathrm{XbaI}$. Insertion of this pro-

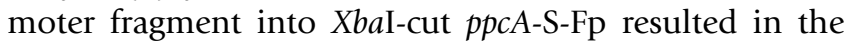
generation of construct $p p c A-\mathrm{PR}_{\mathrm{Fp}}-\mathrm{DR}(+)_{\mathrm{Ft}}$.

For the production of construct $p p c A-\mathrm{PR}_{\mathrm{Ft}} \Delta \mathrm{Intron}-\mathrm{DR}(+)_{\mathrm{Ft}}$ a part of the $p p c A 1$ promoter from $F$. trinervia (-570 to 209) was amplified by PCR with primers S-Ft-F (5'TGCTCTAGACCGGTGTTAATGATGG-3') and S-Ft-R (5'CTGAATATTGGGTATG-CTCAG-3'). Plasmid $p p c A-\mathrm{PR}_{\mathrm{Ft}}{ }^{-}$ $\mathrm{DR}(+)_{\mathrm{Ft}}$ was used as the template for this PCR reaction. The amplified promoter fragment was cut with $X b a \mathrm{I}$. The outermost 3 ' region of the $p p c A 1$ promoter $(-39$ to -1$)$ was generated by annealing the two oligonucleotides S-Ft-3'-1 (5'-GGTTGGAGGGGAATTAAGTATTAAGCAAGGGTGTGAGTAC-3') and S-Ft-3'-2 (5'-CCGGGTACTCACACACCCTTGCTTAATACTTAATTCCCCTCCAACC-3'). Thereby 


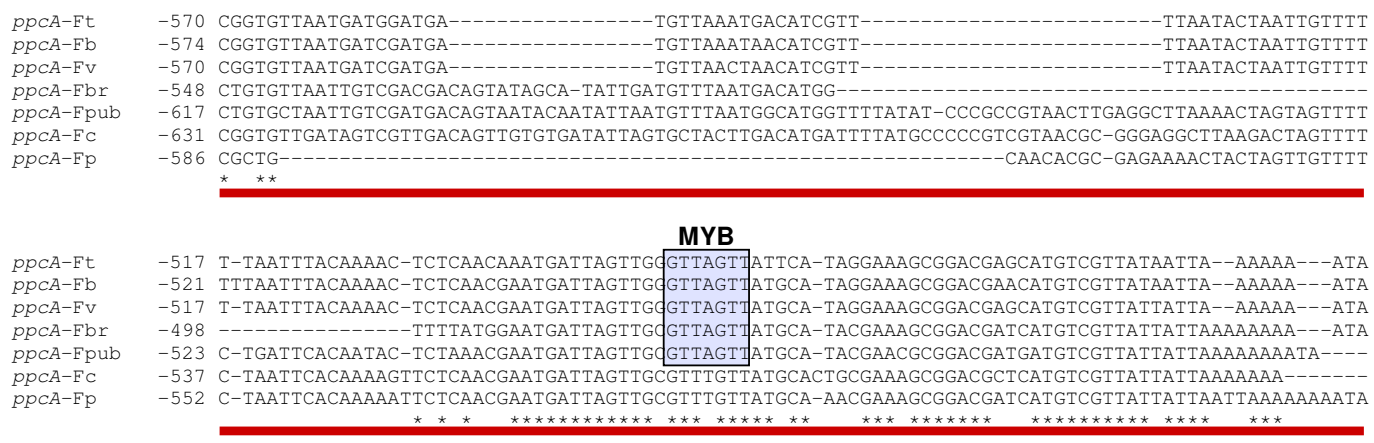

ppCA-Ft $\quad-430$ TCAAAAGAGTAAACAAAAAAGGAAAAAGACTAATTATTTAG---ATAATAATAATATCCACAAAAATATTCGAATTCTTCAATCCTGAGTTTGCT $P P C A-\mathrm{Fb}$ $P D C A-\mathrm{Fv}$ PPCA-Fbr PPCA-Fbr PPCA-FPU PिcA-

-433 TCAAAAGAGTAAACAAAAAAGGAAAAAGACTGATTATTAATATAATAATAATAATATCCACAAAAATATTCGAATTCTTCAATCCTGAGTTTGC -430 TCAAAAGAGTAAACAAAAGAGGAAAAAGACTGAT---TATTAATATAATAATAATATCCACAAAAATATTCGAATGCTTCAAGCCTAAGTTTGCT -423 TCAAAAGAATAAAACATAGAGGAAAAAGACTGAT---TATTAATTTAATAATAATATCCACAAAAATATTCCAATAATTCAACCCTGAGTTTGC -435 TCAAAAGAGTAAAAAATAGAGGAAAAAGACTGAT---TATTAATTTAATAATAATATCCACAAAAATATTCCAATAATTCAACCCTGAGTTTGCT -450 TACTAAGAGTAAAAAATAGAAGTAAAAGACTGAT---TATCAATTTAATAATAATATCCACAAAAATATTCCAATAATTCAACCCTCAGTTTCCT

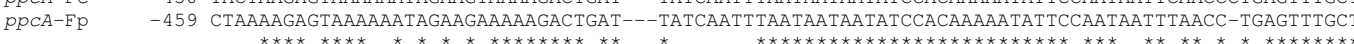

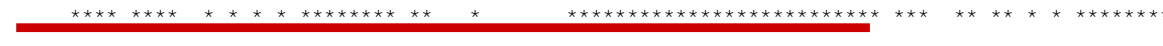

PPCA-Ft

$P D C A-F b$

$P P C A-F V$

ppcA-Fbr

PpCA-Fpub

PDCA-FC

$P P C A-E P$

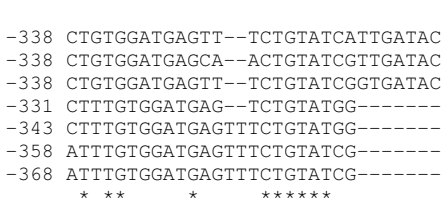

TATA

(1)
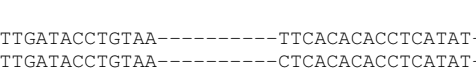

CTCATA TTCATCTATA

(-)
CTCACACACCTCATAT-------CTCATAOTTCATCTATA TTGATACTTGTAA-------CTCACACACTTCATATCTCATAGTCTCATAdTTCATCTATA TTGATACTTGTAAATAATTCAAACTCACACACTTCATATCTCATAGTCTCATACTTCATCTATA

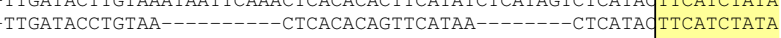

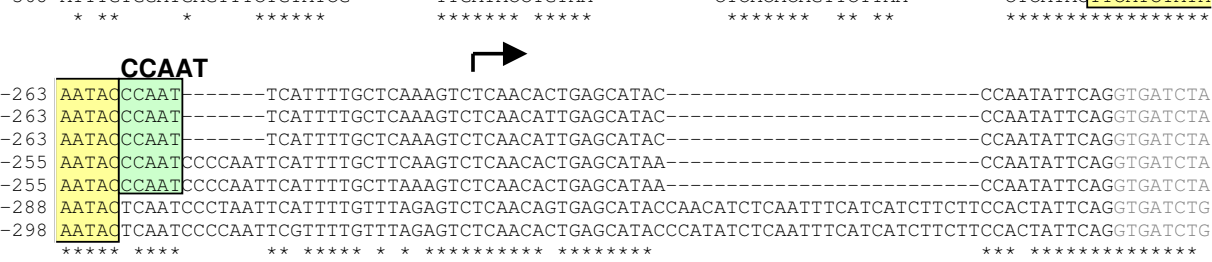

$P P C A-F t$

PPCA-Fb

$P P C A-F v$

ppcA-Fbr

ppcA-Fpub

PPCA-FC

$p p C A-F p$

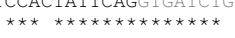

$p p c A-\mathrm{Ft}$
$p p c A-\mathrm{Fb}$
$p p c A-\mathrm{Fv}$
$p p c A-\mathrm{Fbr}$
$p p c A-\mathrm{Fpub}$
$p p c A-\mathrm{Fc}$
$p p c A-\mathrm{Fp}$
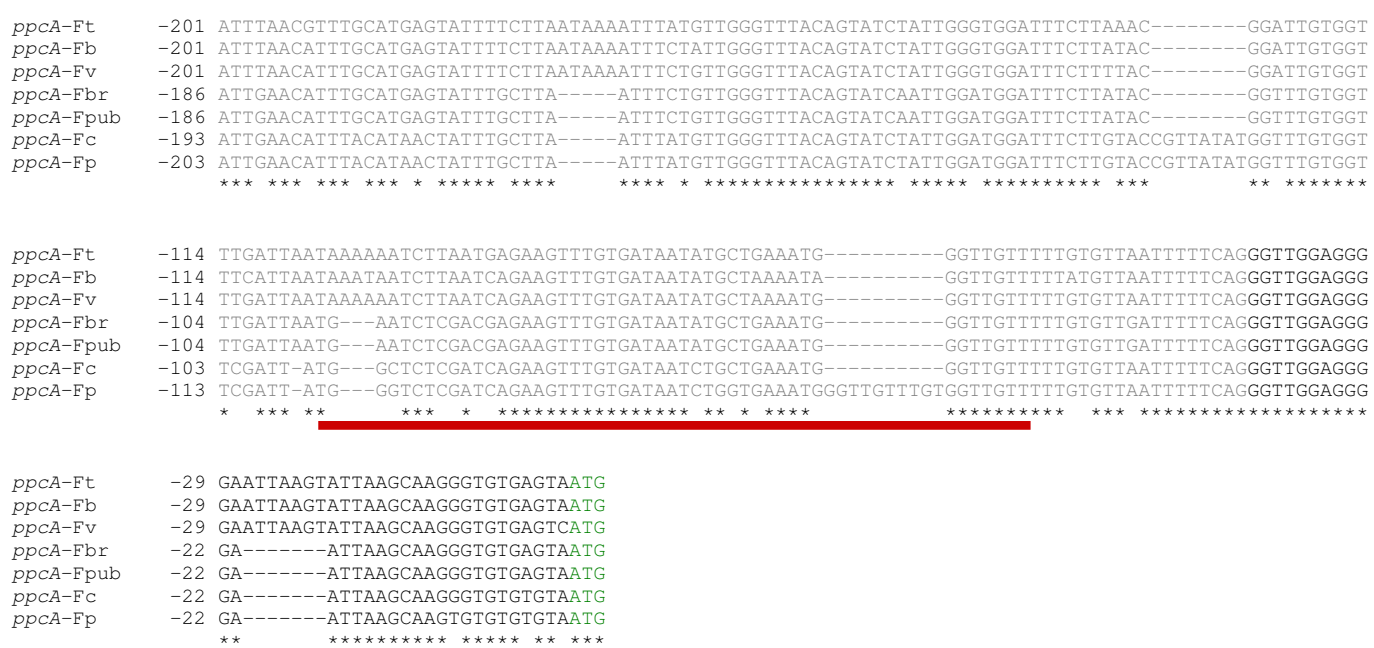

\section{Figure 3}

Nucleotide sequence alignment of the proximal regions of $p p c A$ promoters from $F$. trinervia $\left(C_{4}, p p c A-F t\right), F$. bidentis $\left(C_{4}\right.$, ppcA$\mathrm{Fb}), \mathrm{F}$. vaginata $\left(\mathrm{C}_{4}\right.$-like, ppcA-Fv), $\mathrm{F}$. brownii ( $\mathrm{C}_{4}$-like, ppcA-Fbr), $F$. pubescens $\left(\mathrm{C}_{3}-\mathrm{C}_{4}\right.$, ppcA-Fpub), $F$. cronquistii $\left(\mathrm{C}_{3}, p p c A-\mathrm{Fc}\right)$ and $F$. pringlei $\left(\mathrm{C}_{3}, P p c A-F p\right)$. Identical positions in all $P p c A$ sequences are marked by an asterisk. The intron sequences in the $5^{\prime}$ untranslated leader regions are marked by grey nucleotides. The start site of the $F$. trinervia $p p c A$ transcript is indicated by an arrow, the TATA-box by a yellow box, the putative MYB-binding site by a blue box, and the CCAAT-sequences by a green box. Fragments of the $F$. trinervia PpcAl promoter that interact with the FtHB proteins in the yeast one-hybrid system [14, I5] are marked by red bars. The translational ATG start codon is indicated by green nucleotides. 
a XmaI-compatible 5' overhang was created next to position -1. The ppcA-S-Ft promoter plasmid [39] was digested with $X b a \mathrm{I}$ and $X m a \mathrm{I}$ and the released $p p c A 1$ promoter fragment was removed by agarose gel electrophoresis. The $\mathrm{XbaI} / \mathrm{Xma \textrm {I } - c u t} p p c A-\mathrm{S}$-Ft plasmid was ligated with the two $p p c A 1$ promoter fragments $(-570$ to $-209 /-39$ to -1$)$ and the resulting plasmid was named $p p c A-\mathrm{PR}_{\mathrm{Ft}} \Delta \mathrm{Intron}$. The distal region of the $p p c A 1$ promoter of $F$. trinervia $(-2141$ to -1566$)$ was removed from of $p p c A-\mathrm{PR}_{\mathrm{Ft}}-\mathrm{DR}(+)_{\mathrm{Ft}}$ by incu-

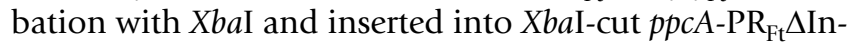
tron. The resulting plasmid was designated $p p c A$ $\mathrm{PR}_{\mathrm{Ft}} \Delta$ Intron $-\mathrm{DR}(+)_{\mathrm{Ft}}$.

\section{Plant transformation}

In all transformation experiments the Agrobacterium tumefaciens strain AGL1 was used [40]. The promoter-GUS constructs were introduced into AGL1 by electroporation. The transformation of Flaveria bidentis was performed as described by Chitty et al. [19]. The integration of the transgenes into the genome of regenerated F. bidentis plants was proved by PCR analyses.

\section{Measurement of GUS activity and histochemical analysis} F. bidentis plants used for GUS analysis were 40 to $50 \mathrm{~cm}$ tall and before flower initiation. Fluorometrical quantification of GUS activity in the leaves was performed according to Jefferson et al. [41] and Kosugi et al. [42]. For histochemical analysis of GUS activity the leaves were cut manually with a razorblade and the sections were transferred to incubation buffer $\left(100 \mathrm{mM} \mathrm{Na}_{2} \mathrm{HPO}_{4}, \mathrm{pH} 7.5\right.$, $10 \mathrm{mM}$ EDTA, $50 \mathrm{mM} \mathrm{K}_{4}\left[\mathrm{Fe}(\mathrm{CN})_{6}\right], 50 \mathrm{mM} \mathrm{K}_{3}\left[\mathrm{Fe}(\mathrm{CN})_{6}\right]$, $0.1 \%(\mathrm{v} / \mathrm{v})$ Triton X-100, 2 mM 5-bromo-4-chloro-3indolyl- $\beta$-D-glucuronid acid). After brief vacuum infiltration the sections were incubated at $37^{\circ} \mathrm{C}$ for 6 to $20 \mathrm{hrs}$. After incubation chlorophyll was removed from the tissue by treatment with $70 \%$ ethanol.

\section{Computer analyses}

DNA sequence analyses were performed with MacMolly Tetra [43]. The sequence alignments were created with the program DIALIGN 2.2.1 [44]. Sequence data mentioned in this article can be found in GenBank under accession numbers $\underline{\text { X64143 }}$ (F. trinervia ppcA1), X64144 (F. pringlei ppcA1), AY297090 (F. vaginata ppcA1), AY297089 (F. cronquistii ppcA1), AY297087 (F. bidentis ppcA1), EF522173 (F. brownii ppcA1) and EF522174 (F. pubescens ppcA1).

\section{Authors' contributions}

SE carried out the histochemical and quantitative GUS assays, the cloning of construct $p p c A-\mathrm{PR}_{\mathrm{Ft}} \Delta \operatorname{Intron}-\mathrm{DR}(+)_{\mathrm{Ft}^{\prime}}$ the sequence alignments and wrote the manuscript. CZ produced construct $p p c A-\mathrm{PR}_{\mathrm{Fp}}-\mathrm{DR}(+)_{\mathrm{Ft}} \cdot \mathrm{MK}$, US and MS performed the transformation of $F$. bidentis. PW coordinated the design of this study and participated in drafting the manuscript. All authors read and approved the final manuscript.

\section{Acknowledgements}

This work was supported by the Deutsche Forschungsgemeinschaft within the SFB 590 "Inhärente und adaptive Differenzierungsprozesse" at the Heinrich-Heine-Universität Düsseldorf.

\section{References}

I. Black CC Jr.: Photosynthetic carbon fixation in relation to net CO2 uptake. Ann Rev Plant Physiol 1973, 24:253-286.

2. Hatch MD: C4 photosynthesis: a unique blend of modified biochemistry, anatomy and ultrastructure. Biochim Biophys Acta 1987, 895:81-106.

3. Latzko $E$, Kelly J: The multi-faceted function of phosphoenolpyruvate carboxylase in C3 plants. Physiol Vég 1983, 21:805-815

4. Kellogg EA: Phylogenetic aspects of the evolution of C4 photosynthesis. In C4 plant biology Edited by: Sage RF and Monson RK. San Diego, Academic; 1999:4I I-444.

5. Hermans J, Westhoff P: Analysis of expression and evolutionary relationships of phosphoenolpyruvate carboxylase genes in Flaveria trinervia (C4) and F. pringlei (C3). Mol Gen Genet 1990, 224:459-468.

6. Kawamura T, Shigesada K, Toh H, Okumura S, Yanagisawa S, Izui K: Molecular evolution of phosphoenolpyruvate carboxylase for C4 photosynthesis in maize: comparison of its cDNA sequence with a newly isolated cDNA encoding an isozyme involved in the anaplerotic function. J Biochem (Tokyo) 1992, I I 2:147-154.

7. Ernst K, Westhoff $P$ : The phosphoenolpyruvate carboxylase (ppc) gene family of Flaveria trinervia (C4) and F. pringlei (C3): molecular characterization and expression analysis of the ppcB and ppcC genes. Plant Mol Biol 1997, 34:427-443.

8. Cretin C, Santi S, Keryer E, Lepiniec L, Tagu D, Vidal J, Gadal P: The phosphoenolpyruvate carboxylase gene family of Sorghum: promoter structures, amino acid sequences and expression of genes. Gene 1991, 99:87-94.

9. Powell AM: Systematics of Flaveria (Flaveriinae-Asteraceae). Ann Mo Bot Gard 1978, 65:590-636.

10. McKown AD, Moncalvo JM, Dengler NG: Phylogeny of Flaveria (Asteraceae) and inference of C4 photosynthesis evolution. Am J Bot 2005, II:1911-1928.

1I. Westhoff P, Gowik U: Evolution of c4 phosphoenolpyruvate carboxylase. Genes and proteins: a case study with the genus Flaveria. Ann Bot (Lond) 2004, 93:13-23.

12. Stockhaus J, Schlue U, Koczor M, Chitty JA, Taylor WC, Westhoff P: The Promoter of the Gene Encoding the C4 Form of Phosphoenolpyruvate Carboxylase Directs Mesophyll-Specific Expression in Transgenic C4 Flaveria spp. Plant Cell 1997, 9:479-489.

13. Gowik U, Burscheidt J, Akyildiz M, Schlue U, Koczor M, Streubel M, Westhoff P: cis-Regulatory elements for mesophyll-specific gene expression in the $\mathrm{C} 4$ plant Flaveria trinervia, the promoter of the C4 phosphoenolpyruvate carboxylase gene. Plant Cell 2004, 16:1077-1090.

14. Windhövel A, Hein I, Dabrowa R, Stockhaus J: Characterization of a novel class of plant homeodomain proteins that bind to the C4 phosphoenolpyruvate carboxylase gene of Flaveria trinervia. Plant Mol Biol 200I, 45:20I-2I4.

15. Windhövel A: Trans-regulatorische Faktoren des C4-Phosphoenolpyruvat-Carboxylase-Gens aus Flaveria trinervia. PhD thesis, Heinrich-Heine-Universität Düsseldorf; I999:I I6-II8.

16. Meshi T, Iwabuchi M: Plant transcription factors. Plant Cell Physiol 1995, 36: | 405-1420.

17. Pabo CO, Sauer RT: Transcription factors: structural families and principles of DNA recognition. Annu Rev Biochem 1992, 61:1053-1095.

18. Chan RL, Gago GM, Palena CM, Gonzalez DH: Homeoboxes in plant development. Biochim Biophys Acta 1998, I442:I-I9.

19. Chitty JA, Furbank RT, Marshall JS, Chen Z, Taylor WC: Genetic transformation of the C4 plant, Flaveria bidentis. Plant J 1994 , 6:949-956. 
20. Roy SW, Gilbert W: The evolution of spliceosomal introns: patterns, puzzles and progress. Nat Rev Genet 2006, 7:2II-22I.

21. Patthy L: Genome evolution and the evolution of exon-shuffling--a review. Gene 1999, 238:103-II4.

22. Le Hir H, Nott A, Moore MJ: How introns influence and enhance eukaryotic gene expression. Trends Biochem Sci 2003, 28:215-220

23. Chang CW, Sun TP: Characterization of cis-regulatory regions responsible for developmental regulation of the gibberellin biosynthetic gene GAI in Arabidopsis thaliana. Plant Mol Biol 2002, 49:579-589.

24. Gadea I, Conejero V, Vera P: Developmental regulation of a cytosolic ascorbate peroxidase gene from tomato plants. Mol Gen Genet 1999, 262:212-219.

25. Kausch AP, Owen TP Jr., Zachwieja SJ, Flynn AR, Sheen J: Mesophyllspecific, light and metabolic regulation of the C4 PPCZm I promoter in transgenic maize. Plant Mol Biol 200I, 45: I-I5.

26. Sheen J: C4 Gene Expression. Annu Rev Plant Physiol Plant Mol Biol 1999, 50:187-217.

27. Sheen J: Metabolic repression of transcription in higher plants. Plant Cell 1990, 2: I027-1038.

28. Engelmann S, Bläsing OE, Gowik U, Svensson P, Westhoff P: Molecular evolution of $\mathrm{C} 4$ phosphoenolpyruvate carboxylase in the genus Flaveria--a gradual increase from $\mathrm{C} 3$ to $\mathrm{C} 4$ characteristics. Planta 2003, 21 7:717-725.

29. Higo K, Ugawa Y, Iwamoto M, Korenaga T: Plant cis-acting regulatory DNA elements (PLACE) database: 1999. Nucleic Acids Res 1999, 27:297-300.

30. Chakravarthy S, Tuori RP, D'Ascenzo MD, Fobert PR, Despres C, Martin GB: The tomato transcription factor Pti4 regulates defense-related gene expression via GCC box and non-GCC box cis elements. Plant Cell 2003, 1 5:3033-3050.

31. Rieping M, Schoffl F: Synergistic effect of upstream sequences, CCAAT box elements, and HSE sequences for enhanced expression of chimaeric heat shock genes in transgenic tobacco. Mol Gen Genet 1992, 23 I:226-232.

32. Edwards D, Murray JA, Smith AG: Multiple genes encoding the conserved CCAAT-box transcription factor complex are expressed in Arabidopsis. Plant Physiol 1998, 1 1 7:1015-1022.

33. Nussinov R: The eukaryotic CCAAT and TATA boxes, DNA spacer flexibility and looping. J Theor Biol 1992, I 55:243-270.

34. Romero I, Fuertes A, Benito MJ, Malpica JM, Leyva A, Paz-Ares J: More than 80R2R3-MYB regulatory genes in the genome of Arabidopsis thaliana. Plant J 1998, I 4:273-284.

35. Riechmann JL, Heard J, Martin G, Reuber L, Jiang C, Keddie J, Adam L, Pineda O, Ratcliffe OJ, Samaha RR, Creelman R, Pilgrim M, Broun P, Zhang JZ, Ghandehari D, Sherman BK, Yu G: Arabidopsis transcription factors: genome-wide comparative analysis among eukaryotes. Science 2000, 290:2105-2110.

36. Yanhui C, Xiaoyuan Y, Kun H, Meihua L, Jigang L, Zhaofeng G, Zhigiang L, Yunfei Z, Xiaoxiao W, Xiaoming Q, Yunping S, Li Z, Xiaohui $D$, Jingchu L, Xing-Wang D, Zhangliang C, Hongya G, Li-jia Q: The MYB transcription factor superfamily of Arabidopsis: expression analysis and phylogenetic comparison with the rice MYB family. Plant Mol Biol 2006, 60:107-124.

37. Akyildiz M, Gowik U, Engelmann S, Koczor M, Streubel M, Westhoff $P$ : Evolution and Function of a cis-Regulatory Module for Mesophyll-Specific Gene Expression in the C4 Dicot Flaveria trinervia. Plant Cell 2007:doi// 0.I I05/tpc. 107.053322.

38. Sambrook J, Russell DW: Molecular Cloning: A Laboratory Manual. , Cold Spring Harbor Laboratory Press.; 200I.

39. Stockhaus J, Poetsch W, Steinmuller K, Westhoff P: Evolution of the $C 4$ phosphoenolpyruvate carboxylase promoter of the C4 dicot Flaveria trinervia: an expression analysis in the $C_{3}$ plant tobacco. Mol Gen Genet 1994, 245:286-293.

40. Lazo GR, Stein PA, Ludwig RA: A DNA transformation-competent Arabidopsis genomic library in Agrobacterium. Biotechnology (N Y) I99I, 9:963-967.

4I. Jefferson RA, Kavanagh TA, Bevan MW: GUS fusions: beta-glucuronidase as a sensitive and versatile gene fusion marker in higher plants. Embo J 1987, 6:390I-3907.

42. Kosugi S, Ohashi $Y$, Nakajima $K$, Arai $Y$ : An improved assay for beta-glucuronidase in transformed cells: Methanol almost completely suppresses a putative endogenous beta-glucuronidase activity. Plant Sci 1990, 70: |33-140.
43. Schoeneberg U, Vahrson W, Priedemuth U, Wittig B: Analysis and interpretation of DNA and protein sequences using MacMolly Tetra. Bielefeld, Germany, KAROI-Verlag Bornemann; 1994.

44. Morgenstern B: DIALIGN: multiple DNA and protein sequence alignment at BiBiServ. Nucleic Acids Res 2004, 32:W33-6.

Publish with BioMed Central and every scientist can read your work free of charge

"BioMed Central will be the most significant development for disseminating the results of biomedical research in our lifetime. "

Sir Paul Nurse, Cancer Research UK

Your research papers will be:

- available free of charge to the entire biomedical community

- peer reviewed and published immediately upon acceptance

- cited in PubMed and archived on PubMed Central

- yours - you keep the copyright
BiolMedcentral 